J. Clin. Chem. Clin. Biochem.

Vol. 26, 1988, pp. 617-622

(C) 1988 Walter de Gruyter \& Co.

Berlin - New York

\title{
Accumulation of Iron and Iron Compounds in Liver Tissue A Comparative Study of the Histological and Chemical Estimation of Liver Iron
}

\author{
By C. van Deursen
}

Department of Internal Medicine,

M. de Metz

Department of Clinical Chemistry and Department of Pathology,

\section{J. Koudstaal}

Department of Pathology and

\section{P. Brombacher}

Department of Clinical Chemistry and Department of Pathology

De Wever-Hospital, Heerlen, The Netherlands

(Received March 12/July 20, 1988)

Summary: Unsatisfactory results obtained by histological evaluation of liver tissue in iron loading diseases prompted us to study the distribution of the total liver iron, haem iron and ferritin iron in post mortem human liver tissue from two different sites of the same liver. The total liver iron content was measured by flameless atomic absorption spectroscopy in native liver homogenates and in acid digested liver tissue from 60 consecutive autopsies, and the results from the two methods were compared. From the standard deviation of the duplicate analyses, it was deduced that the liver iron is possibly inhomogeneously distributed. The $\mathrm{CV}_{\text {duplo }}(22 \%)$ of total iron, measured in acid digested tissue was higher than the $\mathrm{CV}_{\text {duplo }}(14 \%)$ of total iron in homogenates from liver tissue from which non-homogenized tissue e.g. vessel walls, fibrotic tissue, had been removed.

The $\mathrm{CV}_{\text {duplo }}$ of ferritin iron and haem iron in liver homogenate was $14 \%$ and $30 \%$ respectively. The ferritin iron increased with an increasing total iron content until saturation of ferritin iron appeared to be reached at $2.5 \mu \mathrm{g}$ ferritin iron per mg liver protein.

When the results of total non-heam liver iron measurements are expressed properly (amount of iron per amount of homogenized liver protein), the distribution of iron is found to be homogeneous in both normal and pathological liver tissues.

It was concluded that the estimation of liver iron content by visual microscopic evaluation is unsatisfactory, and that more reliable results are obtained by atomic absorption spectrophotometry. 


\section{Introduction}

While the liver is generally viewed as an homogeneous tissue, this is not always the case, especially in pathological conditions (1). In the determination of iron in liver biopsy samples, conflicting results are reported for the sampling error, and it has been stated that there is a rather inhomogeneous distribution of total iron, especially in cirrhosis (2). It is not always clear how the results of one biopsy or consecutive biopsies from patients should be interpreted. Some authors report that the iron content does not differ in needle biopsy specimens taken from the left, right or centre lobes of the liver (3). We presumed that these conflicting data might be method-dependent when the influence of blood contamination is excluded (4).

Traditionally the total iron or non-haem iron contents of the liver are measured chemically in acid digested tissue, and expressed as the amount of iron per amount of tissue weight $(2-5)$. The weight includes functional liver tissue (liver parenchyma), connective tissue (vessels) and possibly fibrotic tissue, whereas the iron is mainly stored in functional liver tissue (6). It is the iron in this latter tissue, which induces the harmful effects of iron overloading, such as fibrosis and possibly cirrhosis of the liver.

Moreover, the presence of fat and connective tissue (fibrosis, cirrhosis) will have its impact on the iron concentration in situ. Hence measurement of liver iron in functional liver tissue is preferred.

Our main interest is in partients with idiopathic haemochromatosis or haemosiderosis; the liver iron contents in these patients are of primary importance for diagnosis and therapy $(6,7)$.

The diagnosis of haemochromatosis or haemosiderosis is made after histological examination and histochemical iron staining of liver biopsies. However, the degree of iron staining in histological slides does not necessarily reflect the total amount of iron present, which can be measured by chemical procedures after tissue destruction. For example, in Perl's staining method there is a difference in staining intensity between ferritin and haemosiderin iron, while transferrin is not stained at all (8). This accounts for the poor correlation of results between histochemical and chemical methods for iron detection $(9,10)$. From a physiological point of view, iron overloading leads to an excess of ferritin and the formation of haemosiderin, which is easily stainable and very important for determining the degree of haemochromatosis (7). Chemical methods for iron analysis should therefore discriminate between haemosiderin and ferritin iron. In the present work a method for iron analysis in functional liver tissue, using graphite furnace atomic absorption spectroscopy is presented, which also fulfills the above mentioned prerequisites for chemical iron analysis. This method was compared with a method based on acid digestion of liver tissue, and the distribution of iron was studied.

\section{Materials and Methods}

\section{Liver tissue and sample preparation}

Fresh human liver tissue from the right and left lobe was obtained from 60 consecutive autopsies. A portion of the tissue was processed for routine histological examination. The tissue was cut into small pieces (approx. $10 \mathrm{mg}$ ), frozen in liquid nitrogen and stored at $-80^{\circ} \mathrm{C}$. Thawed material was washed three times with $15 \mathrm{ml}$ ice cold isotonic saline for $5 \mathrm{~min}$. For mineralisation, the washed tissue was dried $\left(110^{\circ} \mathrm{C}, 2 \mathrm{~h}\right)$, weighed and decomposed at $90^{\circ} \mathrm{C}$ for $2 \mathrm{~h}$ in a mixture of concentrated sulphuric acid and nitric acid in a ratio of $1+1$ (by vol.). Approximately $1 \mathrm{ml}$ of decomposition mixture was added to $25 \mathrm{mg}$ of liver tissue (dry weight).

Liver homogenate was prepared in $200 \mu \mathrm{H}_{2} \mathrm{O}$ per $10 \mathrm{mg}$ washed liver tissue by 20 strokes with a loose fitting pestle in a glass homogenizer. The homogenate was strained to remove non-homogenized material such as connective tissue etc. before the measurement of total iron (vide infra) and protein (11).

\section{Atomic absorption spectroscopy}

Flameless atomic absorption measurements were performed on a Perkin Elmer (Überlingen, F. R. G.) model 3030 spectrophotometer with deuterium background correction, equipped with a PE HGA 500 graphite furnace atomizer (programmable) and a PE AG 40 autosampler. The iron hollow cathode lamp was from Instrumentation Laboratory no. 89225 (Paderno, Italy). Due to the analytical sensitivity of this type of analysis, the samples (acid digested liver tissue or liver homogenate) must be diluted at least 200 times (by vol.) with $200 \mathrm{mmol} / \mathrm{l}$ ammonium acetate containing $30 \mathrm{mmol} / 1$ nitric acid before analysis. In this way the method is also perfectly suitable for the analysis of needle biopsies, as never more than an equivalent of $0.2 \mathrm{mg}$ tissue is required. The measurement was performed according to Kreeftenberg et al. (2) with some modifications as described in table 1.

Tab. 1. Instrumental conditions for the determination of iron in liver tissue by flameless atomic absorption spectrophotometry.

Sample volume $20 \mu \mathrm{l}$

Fe-hollow cathode lamp $15 \mathrm{~mA}$

Slit width $0.2 \mathrm{~nm}$, alternate

Wavelength $248.8 \mathrm{~nm}$

Deuterium background corrector on

Graphite furnace tube with $L^{\prime}$ 'vov platform, pyrolytic coated Purge gas, argon: $300 \mathrm{ml} / \mathrm{min}$.

$\begin{array}{lrrrrr}\text { Dry cycle } & 130^{\circ} \mathrm{C} & 10 \mathrm{~s} & \text { ramp } & 20 \mathrm{~s} & \text { hold } \\ \text { Char cycle } & 250^{\circ} \mathrm{C} & 10 \mathrm{~s} & \text { ramp } & 5 \mathrm{~s} & \text { hold } \\ & 850^{\circ} \mathrm{C} & 10 \mathrm{~s} & \text { ramp } & 5 \mathrm{~s} & \text { hold } \\ & 1400^{\circ} \mathrm{C} & 6 \mathrm{~s} & \text { ramp } & 10 \mathrm{~s} & \text { hold } \\ & 2400^{\circ} \mathrm{C} & 0 \mathrm{~s} & \text { ramp } & 5 \mathrm{~s} & \text { hold } \\ \text { Atomize cycle } & 2700^{\circ} \mathrm{C} & 1 \mathrm{~s} & \text { ramp } & 3 \mathrm{~s} & \text { hold }\end{array}$

Signal processing, peak area, $3 \mathrm{~s}$ after start atomize cycle. Gas flow, interrupt at atomization. 
Calibration mixtures were prepared from a ferric nitrate standard solution $(178 \mu \mathrm{mol} / \mathrm{l})$ in $200 \mathrm{mmol} / \mathrm{l}$ ammonium acetate containing $30 \mathrm{mmol} / \mathrm{l}$ nitric acid. A linear calibration was obtained with mixtures with $0,0.53,1.07$ and $1.61 \mu \mathrm{mol} / 1$ iron. Precision of the method was monitored with acid digested liver homogenate, stored at $-80^{\circ} \mathrm{C}$ in polypropylene cups.

\section{Ferritin and haem iron}

Haem iron is measured colorimetrically as haemicyanide after extraction, as described by Zuyderhoudt et al. (4). Liver ferritin was isolated from homogenates (protein concentration ca. $4 \mathrm{~g} / \mathrm{l}$ ) by heat treatment $\left(70-75^{\circ} \mathrm{C}, 5 \mathrm{~min}\right)$ and centrifugation as described by Zuyderhoudt et al. (4). Ferritin iron was measured in the supernatant, after dilution with $200 \mathrm{mmol} / \mathrm{l}$ ammonium acetate, $30 \mathrm{mmol} / 1 \mathrm{nitric}$ acid. Ferritin protein was measured with an immunoenzymatic assay of Hybritech Europe (Liège, Belgium) according to the manufacturer's instructions. The percentage of iron core in the ferritin molecule was calculated as $(\mathrm{FeOOH})_{8} \mathrm{FeO}_{3} \mathrm{PO}_{2} \mathrm{H}_{2}$ per ferritin protein (12).

\section{Histological examination}

The 46 samples of liver tissue were also processed for histologial examination, and iron was stained by the Prussian blue reaction (Perl's staining). The iron content was graded according to the modified Rowe system (13), i. e. visual evaluation of iron staining by microscopy and classification into five grades according to intensity of staining in relation to the magnification.

\section{Reagents}

Unless specified outherwise, all reagents were purchased from Merck (Darmstadt, FRG).

\section{Results}

The influence of sample preparation on the total iron analysis

The influence of acid digestion was studied by comparing the iron determination in native homogenate and dried and acid-treated homogenate. This results in a correlation coefficient of 0.98 (fig. 1).

A comparison between iron, which is determined in dried, weighed and acid digested tissue (including nonhomogenized material) and iron, which is determined in native homogenate (without non-homogenized material) results in a correlation coefficient of 0.93 (fig. 2).

\section{Liver iron content}

The distribution of the liver iron content is shown in table 2. Ferritin iron and protein were measured in 10 randomly selected liver homogenates; the iron core in the ferritin molecules was $0.21 \pm 0.05(\bar{x}+2 \mathrm{SD})$, as calculated by the ratio of the total iron content to total ferritin. Haem iron in congested livers $(n=4)$ was first measured separately, but as these data were in good agreement with those obtained from other

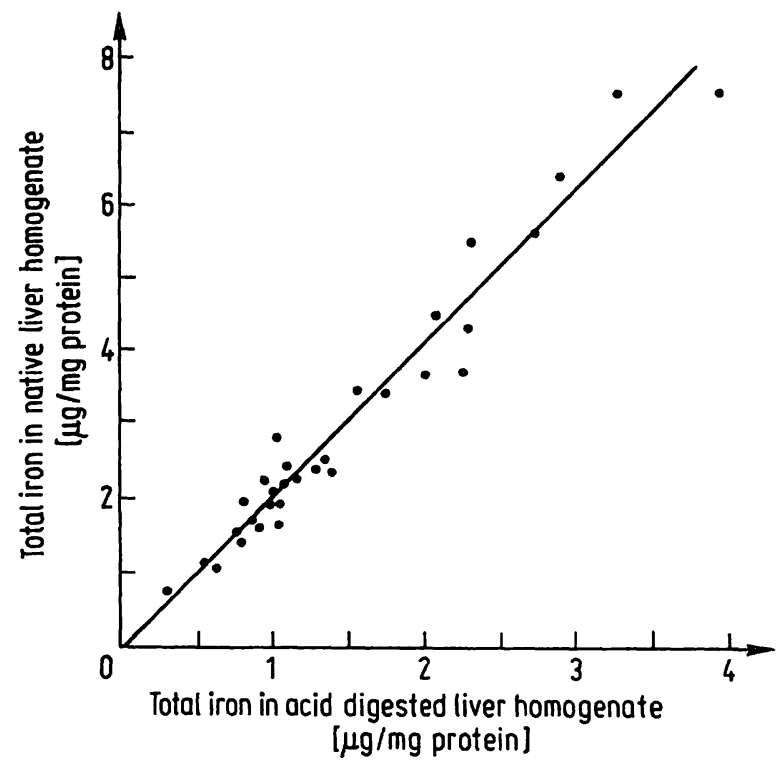

Fig. 1. Comparison of the iron contents, measured in native liver homogenate ( $y$-axis) and acid digested homogenate (x-axis).

$\mathrm{y}=1.06 \mathrm{x}-0.21, \mathrm{n}=31, \mathrm{r}=0.98$

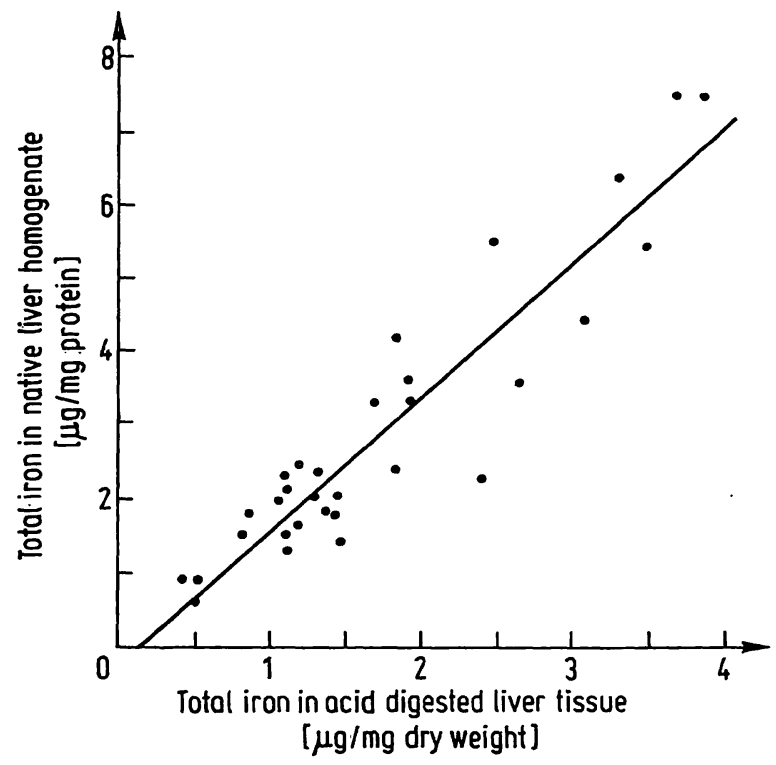

Fig. 2. Comparison of the iron contents measured in native liver homogenate ( $y$-axis) and acid digested, dried liver tissue ( $\mathrm{x}$-axis)

$\mathrm{y}=1.76 \mathrm{x}-0.32, \mathrm{n}=31, \mathrm{r}=0.93$

Tab. 2. Liver iron content

\begin{tabular}{lll}
\hline & \multicolumn{2}{l}{ Iron content $(\mu \mathrm{g} / \mathrm{mg}$ protein $)$} \\
\cline { 2 - 3 } & $\overline{\mathrm{x}} \pm \mathrm{SD}$ & Range \\
\hline Total iron $(\mathrm{n}=60)$ & $2.4 \pm 1.6$ & $0.2 \pm 8.3$ \\
Ferritin iron $(\mathrm{n}=56)$ & $1.2 \pm 0.7$ & $0.1 \pm 3.3$ \\
Haem iron $(\mathrm{n}=36)$ & $0.3 \pm 0.1$ & $0.1 \pm 0.8$ \\
\hline
\end{tabular}


livers, they were included in the total group. The samples with a low total iron content contain predominantly ferritin iron and haem iron, and hardly any haemosiderin iron. With increasing iron stores, the ferritin iron increases, but above a total iron content of ca. $3 \mu \mathrm{g} / \mathrm{mg}$ protein most iron is stored in insoluble compounds e. g. haemosiderin (fig. 3), which accounts for the difference between total iron and the sum of ferritin plus haem iron.

\section{Influence of sampling}

A fundamental problem in the determination of differences between the iron contents of different samples is that the comparison of analysis results is always influenced by the technical accuracy of the studied data. With insufficient analytical accuracy the possibility arises that real differences between samples may escape observation, or that observed small differences are due to analytical errors.

This problem was investigated by comparison of two remote tissue samples from the same liver with two samples from the same slice. We found that differences in iron concentrations between liver homogenates from different samples (method I) were smaller than differences between samples after acid decomposition (method II) and this was invariably found for both the samples from remote parts of the liver and for samples from the same locus (tab. 3). Moreover, taking into account the within-day coefficient of variation of the analysis $\left(\mathrm{CV}_{\text {within-day }} 4.5 \%\right)$, the differences between homogenates of samples from the same locus appeared to be small.

\section{Histology}

The results of the chemical liver iron determination were plotted against the grades of iron staining found by histological examination (fig. 4). A poor correlation between these two assessments of the liver iron content was observed. There is a considerable range of chemically determined values in the histological grade $0-2$. The overlap of histological grades for a given chemically determined value is conspicuous.

\section{Discussion}

As stated in the introduction, the liver iron content should be expressed as the amount of iron per amount of functional liver tissue and not per total tissue weight (wet or dry). This requirement can be approximately met by iron determination in liver homogenates, from which collagenous tissue has been removed. In addition, if the iron is expressed per $\mathrm{mg}$ protein the presence of fat deposits will have no in-

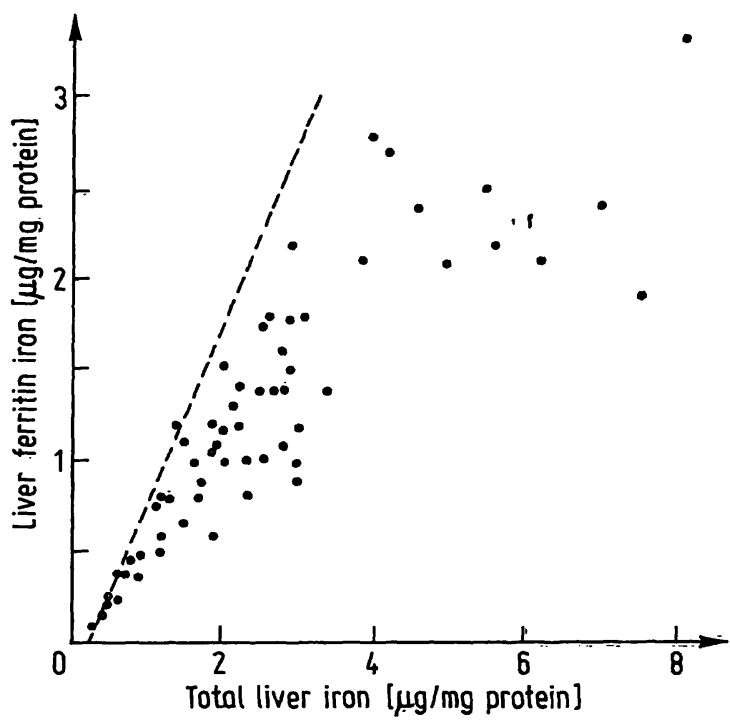

Fig. 3. Correlation between total liver iron and liver ferritin iron in native liver homogenate. The dashed line represents the hypothetical outcome if all the liver iron is stored as ferritin iron and $0.3 \mu \mathrm{g} / \mathrm{mg}$ protein as haem iron.

Tab. 3. Influence of sampling on the measurement of iron in liver tissue.

Total liver iron, ferritin iron and haem iron were measured in two samples from the same liver after homogenization (method I). Total liver iron was also measured after drying, weighing and acid digestion of the tissue (method II).

\begin{tabular}{lll}
\hline Iron analysis & \multicolumn{2}{l}{ CV duplo (percentage) } \\
\cline { 2 - 3 } & Remote parts & Local site \\
\hline Total iron $(\mathrm{n}=60)$ & & 8 \\
$\quad$ method I & 14 & 26 \\
$\quad$ method II & 22 & 10 \\
Ferritin iron $(\mathrm{n}=56)$ & 14 & - \\
Haem iron $(\mathrm{n}=36)$ & 30 & \\
\hline
\end{tabular}

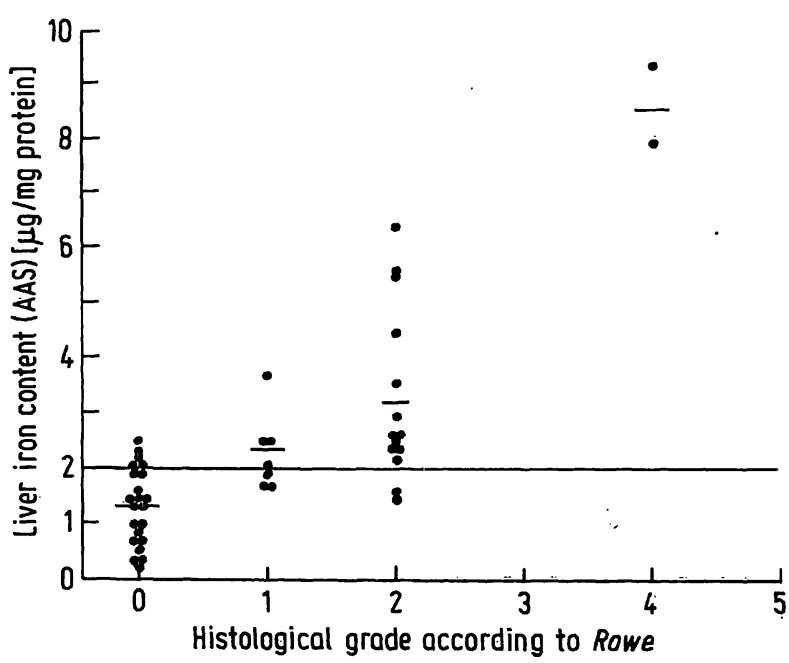

Fig. 4. Liver iron content (atomic absorption spectrophotometry, AAS) in preparations with different histological grades (Rowe grading system). 
fluence on the results. Moreover, the precison of iron determination in homogenates is better than in dried tissue samples (tab. 3, method I vs method II). Method comparison also shows that a better correlation coefficient is obtained between two iron determinations in homogenates freed from connective tissue etc. (designated as "functional tissue homogenates", fig. 1), than between an iron determination in functional tissue $v s$ in total liver tissue (fig. 2). This might be explained by the inhomogeneous distribution of tissue components like vessel walls, bile ducts, fibrotic (sclerotic) tissue and fat deposits. Only a few data are available from other publications on the distribution of iron at separate sites in the same liver, and in these publications, method dependency is not taken into account. It must be concluded from our results (tab. 3) that a large sampling error is not to be expected, when iron is appropriately measured, so that analytical bias does not really contribute to the observed differences. A correction for haem iron at low total iron contents might be needed, because blood clots can be distributed non-homogeneously in the liver tissue.

When the iron content is measured with flameless atomic absorption spectroscopy, sample preparation by destruction of tissue with strong acid before introducing it into the graphite furnace is not necessary. The instrument setting can be chosen to minimize matrix effects and imprecision. This is shown in figure 1 , where iron determinations in native liver homogenate and in acid digested homogenate are compared. The correlation is good $(r=0.98)$, but since acid digestion may accidentally introduce contamination, we prefer a direct analysis of liver homogenate. Moreover, in flameless atomic absorption a sample size of over $0.2 \mathrm{mg}$ tissue is never required, so that needle biopsies can always be investigated.

A comparison of results for the iron content from different laboratories is often only possible after recalculation. For this recalculation we assumed that fresh liver tissue contains $80 \%$ water and that $50 \%$ of the dry weight is protein. When our data (tab. 2) are compared with the values found in the literature for a reference group $(6,10)$, higher values for the iron content are to be expected, because the liver tissue was obtained post mortem from elderly people. The liver iron content increases with age (14), whereas the haem iron content is somewhat higher in post mortem material than in fresh biopsy specimens (4).

Ferritin iron and ferritin protein were measured in the supernatant of heat denatured liver homogenates. This fraction contains to a large extent the total nonhaem iron pool in normal individuals $(15-18)$. The iron core in the ferritin molecule can also be calculated and values between 0.10 and 0.40 of iron have been reported $(4,18)$. We have found an average iron core in ferritin of 0.21 and will continue to measure this parameter routinely in biopsies. Although its clinical relevance is unclear, the data might be used for quality control purposes.

A correlation between the total iron content and the ferritin iron is depicted in figure 3. A more or less linear correlation is seen up to a total iron concentration of $3 \mu \mathrm{g} / \mathrm{mg}$ protein. This value is approximately in agreement with the value for the hepatic iron concentration above which values must be considered abnormal (10). The ferritin iron appears to be relatively constant at elevated total iron concentrations, whereas insoluble iron (haemosiderin) increases. The increase in haemosiderin iron seems to be prognostic for toxic effects of iron overloading (7), but the clinical implication of the measurement of the ferritin iron/ haemosiderin iron ratio for the individual patients needs to be evaluated.

The increase in ferritin iron to a certain level and the concurrent increase in the ferrition iron/haemosiderin ratio was also found by Selden et al. $(15,17)$, although they use a chromatographic method for the separation of haem iron, ferritin iron and haemosiderin in liver biopsies and focus on heavy iron overloading ( $\mathrm{Fe}$ above $10 \mu \mathrm{g} / \mathrm{mg}$ protein). Zuyderhoudt et al. (18) could not confirm that the ratio ferritin iron/haemosiderin fell with increasing iron overload. They suggest that storage conditions might be reponsible for this discrepancy, but we could not validate this. We could, however, not exclude the possibility that part of the ferritin becomes less soluble post mortem (before freezing the tissue) and is then determined as insoluble haemosiderin.

It is apparent that the histological iron grading is insufficient for a precise and accurate evaluation of the liver iron content. There is a considerable overlap between various histological grades in samples with comparable iron contents as determined by chemical analysis.

For better understanding, chemical methods of iron analysis have to include the determination of the different forms of iron and iron compounds. In this paper we have described chemical methods, but in our laboratory we also recently introduced a histochemical method for ferritin staining, in addition to iron staining with Perls blue. It now seems that earlier reported discrepancies between data obtained either by chemical or by histochemical methods for iron analysis $(9,10)$ may be due to hitherto insufficient knowledge of the nature and distribution of the iron compounds concerned. 


\section{References}

1. Maharaj, B., Maharaj, R. J., Leary, W. P., Cooppan, R. M., Naran, A. D., Pirie, D. \& Pudifin, D. J. (1986) Lancet 1, 523-525.

2. Kreeftenberg, H. G., Koopman, B. J., Huizenga, J. R., van Vilsteren, T., Wolthers, B. G. \& Gips, C. H. (1984) Clin. Chim. Acta 144, 255-262.

3. van Eijk, H. G., Wiltink, W. F., Gre Bos \& Goossens, J. P. (1974) Clin. Chim. Acta 50, 275-280.

4. Zuyderhoudt, F. M. J., Hengeveld, P., van Gool, J. \& Jörning, G. G. A. (1978) Clin. Chim. Acta 86, 313-321.

5. Barry, M. \& Sherlock, S. (1971) Lancet $I, 100-103$.

6. Gollan, J. L. (1983) Gastroenterology 84, 418-421.

7. Tavill, A. S. \& Bacon, B. R. (1986) Hepatology 6, 142145.

8. Richter, G. W. (1978) Am. J. Pathol. 91, 363-396.

9. Brissot, P., Bourel, M., Herry, D., Verger, J. P., Messner, M. Beaumont, C., Regnouard, F., Ferrand, B. \& Simon, M. (1981) Gastroenterology 80, 557-565.

10. Edwards, C. Q., Caroll, M., Bray, P. \& Cartwright, G. E. (1977) N. Eng. J. Med. 297, 7-13.
11. Lowry, O. M., Rosebrough, N. J., Farr, A. L. \& Randall, R. J. (1951) J. Biol. Chem. 193, 265-275.

12. Zuyderhoudt, F. M. J., Linthorst, C. \& Hengeveld, P. (1978) Clin. Chim. Acta 90, 93-99.

13. Searle, J. W., Kerr, J. F. R., Halliday, J. W. \& Powell, L. W. (1987) Iron storage disease. In: Pathology of the liver (MacSween, K. N. M., Anthony, P. P. \& Scheuer, P. J., eds.) 2nd ed. pp. 181-201. Churchill Livingstone, Edinburgh, London, Melbourne and New York.

14. Bassett, M. L., Halliday, J. W. \& Powell, L. W. (1986) Hepatology $6,24-29$.

15. Cham, B. E., Roeser, P., Nikles, A. C. \& Ridgway, K. M. (1986) Clin. Chim. Acta 158, 71-79.

16. Selden, C., Owen, M., Hopkins, J. M. P. \& Peters, T. J. (1980) Br. J. Haematol. 44, 593-603.

17. Selden, C. \& Peters, T. J. (1979) Clin. Chim. Acta 98, $47-52$.

18. Zuyderhoudt, F. M. J., Sindram, J. W., Marx, J. J. M., Jörning, G. G. A. \& van Gool, J. (1983) Hepatology 3, $232-235$.

Prof. Dr. P. J. Brombacher

Department of Clinical Chemistry

De Wever-Ziekenhuis

P. O. Box 4446

NL 6401 CX Heerlen 